\title{
Control of ovarian follicular and corpus luteum development for the synchronization of ovulation in cattle
}

\author{
WW Thatcher ${ }^{1}$ and JEP Santos ${ }^{2}$ \\ 'Department of Animal Sciences, University of Florida, Gainesville, FL, USA and 'Veterinary Medicine \\ Teaching and Research Center, University of California-Davis, Tulare, CA, USA.
}

The objective of this review is to integrate strategies to optimize an ovulatory control program which then serves as a platform to improve the reproductive performance of lactating dairy cows. Programmed management of follicle growth, regression of the $\mathrm{CL}$ and induction of ovulation led to development of the Ovsynch program. Presynchronization of estrous cycles followed 12 to 14 days later with the Ovsynch program increased pregnancy rates to timed inseminations. Initiation of the Ovsynch program on day 3 of the estrous cycle reduced ovulation to $\mathrm{GnRH}$ and resulted in a smaller proportion of excellent and good quality embryos following timed insemination. The pregnancy rate to a timed insemination of Ovsynch was greater when cows ovulated to the first injection of GnRH. The Presynch-Ovsynch program provided a platform to identify factors regulating reproductive performance; such as, parity, body condition score and anovulation. Treatment with hCG at day 5 after insemination increased pregnancy rate in lactating dairy cows. Injection of bovine somatotropin at insemination increased pregnancy rate, conceptus length and interferon- $\tau$ content in uterine luminal flushings and altered endometrial gene expression at day 17 of pregnancy. During heat stress, timed embryo transfer increased pregnancy rate and using embryos cultured with IGF-I and transferred fresh resulted in a greater pregnancy rate. Induction of ovulation with estradiol cypionate, as a component of a timed insemination program, increased fertility. Manipulation of the estrous cycle to improve follicle/oocyte competence and management of the post-ovulatory dialogue between embryonic and uterine tissues should enhance embryo development and survival.

\section{Introduction}

The goal of a successful estrous synchronization program is precise control of estrus and ovulation allowing fixed-time artificial insemination (AI) with high fertility. Lactating dairy cows usually benefit the most from synchronization programs as herd pregnancy rates (PR; defined as the proportion of pregnant cows relative to all eligible cows inseminated or not in a given period of time) are often times low because of poor estrous detection, occurrence of anestrus 
and low conception rates. As our knowledge regarding control of the estrous cycle has been expanded, appropriate implementation of physiological methods to control sequentially folJicle turnover, CL regression and induction of ovulation have been successful (Thatcher et al. 2004). Prostaglandins alone do not provide acceptable synchrony because the time of ovulation depends on the stage of development of the dominant follicle at the time of the prostaglandin-induced regression of the CL. This problem has been resolved partially with the development of the Ovsynch protocol as a breeding strategy that eliminates the need for detection of estrus whilst allowing for timed Al (Pursley et al. 1997). The protocol is composed of an injection of $\mathrm{GnRH}$ at random stages of the estrous cycle to induce ovulation of the dominant follicle and synchronize the emergence of a new follicular wave. Seven days later, PGF ${ }_{2 \alpha}$ is given to regress both the original and the potential newly formed $\mathrm{CL}$, followed by a second $\mathrm{GnRH}$ injection $48 \mathrm{~h}$ later to induce a synchronous ovulation approximately 28 to $32 \mathrm{~h}$ later. A timed $\mathrm{Al}$ (TAl) is done at 12 to $16 \mathrm{~h}$ after the second $\mathrm{GnRH}$ injection. Pregnancy rates are comparable to those of cows inseminated at detected estrus. This protocol has been implemented successfully in many commercial dairy farms world wide as a strategy for TAl during the first postpartum Al, as well as for re-insemination of non-pregnant cows. Although the Ovsynch protocol allows for TAI without the need for estrous detection, approximately 10 to $15 \%$ of the cows will display signs of estrus during the protocol and they should be inseminated promptly if maximum PR is to be achieved.

The objective of this review is to integrate strategies to further optimize an ovulatory control program that is applicable to lactating dairy cows and to define how it can be utilized as a platform to improve the reproductive performance of a dairy herd.

\section{Strategies to further optimize an ovulation control program}

Pre-synchronization

Vasconcelos et al. (1999) noted that initiation of the Ovsynch protocol between days 5 and 9 of the cycle resulted in the highest frequency of ovulation to the first GnRH injection. Fertility was decreased when the duration of dominance of the ovulatory follicle was longer than 5 days (Austin et al. 1999) or the Ovsynch program was initiated in the early stages of the estrous cycle (Vasconcelos et al. 1999). Ovulation to the first GnRH injection and initiation of a new follicular wave should improve PR because an ovulatory follicle with a reduced period of dominance is induced to ovulate. Thus the concept of pre-synchronization (Presynch; Moreira et al. 2001) was introduced to enhance the probability of having a dominant follicle ( $\geq 10 \mathrm{~mm}$ ) that will be induced to ovulate to the first GnRH injection of the Ovsynch protocol and the assurance that a $\mathrm{CL}$ will be present throughout the synchronization period (that is, a $\mathrm{CL}$ will not regress prior to the injection of $\left.\mathrm{PGF}_{2 \alpha}\right)$. The Presynch-Ovsynch program utilizes two injections of $\mathrm{PGF}_{2 \alpha} 14$ days apart, with the second injection given 12 days prior to the first GnRH of the TAl protocol. The Presynch-Ovsynch program increased PR 18 percentage units (that is, $25 \%$ to $43 \%$ ) in lactating cyclic cows (Moreira et al. 2001). Likewise, El-Zarkouny et al. (2004) also demonstrated improvement in PR when cows were pre-synchronized prior to the Ovsynch protocol. In addition to the potential benefit of optimizing the stage of the cycle by presynchronization, the prior repeated injections of $\mathrm{PGF}_{2 \alpha}$ may have a therapeutic benefit on the uterine environment by stimulating re-occurring proestrous/estrous phases allowing for improved uterine defense mechanisms.

Navanukraw et al. (2004) demonstrated that pre-synchronizing cows with 2 injections of $\mathrm{PGF}_{2 \alpha^{\prime}}$ the second given 14 days prior to initiation of the Ovsynch protocol, improved PR. 
Pregnancy rate to the modified Presynch-Ovsynch program was greater than the Ovsynch program $(49.6 \%>37.3 \% ; P<0.05)$. This slight modification makes the sequence of injections friendlier to producers as injections are given on a weekly basis.

\section{Optimizaton of follicle turnover}

Implementation of the Ovsynch protocol prior to day 10 of the estrous cycle reduced the number of cows with premature luteolysis (Vasconcelos et al. 1999) and would therefore be expected to minimize the number of cows expressing estrus prior to the second GnRH injection and ovulating prematurely prior to the time of Al. However, it does not control precisely the stage of follicle development at the time of the first injection of GnRH in the Ovsynch protocol. Regardless of pre-synchronization strategies, cows that ovulated to the first GnRH injection of the Ovsynch protocol had increased PR (Chebel et al. 2006). In cows subjected to a Presynch-Ovsynch protocol, with the first GnRH of the Ovsynch protocol given 13 days after the Presynch (which in this study utilized CIDRs [+] or no CIDRs [-]), those ovulating to the GnRH had increased PR at 31 (+ CIDR, 37\% > - CIDR, 21\%) and $60(+$ CIDR, $28 \%>-$ CIDR, $18 \%$ ) days after Al (Chebel et al. 2006).

The importance of inducing follicle turnover is demonstrated vividly by evaluating fertilization rates and embryo quality after TAl following the induction of follicle turnover or not (Cerri et al. 2005a). Our hypothesis was that initiating Ovsynch on day 3 of the estrous cycle would lead to continued development of an ovulatory follicle that would result in poorer embryo quality compared to recruitment of a new ovulatory follicle following follicle turnover initiated by an injection of $\mathrm{GnRH}$ on day 6 of the cycle. Lactating cows $(n=396)$ were subjected to Al after one of four protocols (Fig. 1). All cows received the same pre-synchronization protocol. The first group, called "Detected estrus (DE)", received GnRH on day 6 of the estrous cycle, followed by $\mathrm{PGF}_{2 \alpha} 7$ days later and $\mathrm{Al}$ upon estrus. The other three groups were all subjected to an Ovsynch protocol (that is, GnRH, 7 days later $\mathrm{PGF}_{2 \alpha^{\prime}} 2$ days later GnRH followed by TAl $12 \mathrm{~h}$ later). The difference between these three goups, OV 3, OV 6 and OVE, was the timing of the first injection of $\mathrm{GnRH}$ on days 3, 6 and 6 of the estrous cycle, respectively. Group OVE also received an injection of $0.5 \mathrm{mg}$ of estradiol cypionate (ECP) $36 \mathrm{~h}$ before the TAI. The same technician inseminated all cows with semen from a single sire. Ovarian responses were evaluated by ultrasonography, blood was analyzed for progesterone and uteri were flushed on day 6 after Al. The incidence of ovulation in response to the first injection of GnRH was less for cows receiving $\mathrm{GnRH}$ on day 3 than on day 6 of the estrous cycle (OV3 $=7.1 \%$ compared to $\mathrm{DE}=79.2 \%, \mathrm{OV} 6=87.3 \%, \mathrm{OVE}=85.2 \% ; \mathrm{P}<0.001$ ) because of smaller dominant follicles $(\mathrm{OV} 3=9.5<\mathrm{DE}=14.2, \mathrm{OV} 6=15.4$ and $\mathrm{OVE}=15.0 \mathrm{~mm}$ in diameter; $\mathrm{P}<0.001)$. A new follicular wave was observed in less cows when the first injection of $\mathrm{GnRH}$ was administered on day 3 compared with day 6 (OV $3=7.1 \%$ compared to $\mathrm{DE}=81.2 \%, \mathrm{OV} 6=88.6 \%$ and $\mathrm{OVE}=88.9 \% ; \mathrm{P}<0.001)$. The diameter of the ovulatory follicle at Al differed $(20.7,19.7,18.1$ and $19.7 \mathrm{~mm}$ for OV3, DE, OV6 and OVE, respectively; $\mathrm{P}<0.001$ ). Growth of the dominant follicle that did not turnover (that is, OV3) and the fresh dominant follicle that was allowed to ovulate spontaneously (that is, DE) grew to a larger size and reflected the differences in the duration of follicular dominance $(8.1,7.3,5.8$ and 5.7 days for OV3, DE, OV6 and OVE, respectively; $\mathrm{P}<0.001)$. The proportion of cows synchronized at $\mathrm{Al}$ (luteolysis and ovulation) was greater for DE $(96.9 \%)$ than the TAI treatments $(84.1 \%)$.

Non-synchronized cows in TAl protocols were not flushed on day 6 after Al. Those cows not observed in estrus in the DE group were not inseminated and, therefore, not flushed on day 6 after $\mathrm{Al}$. Fertilization rates were similar $(\mathrm{P}=0.96)$ and averaged $86.3 \%$ across treatments. Of 


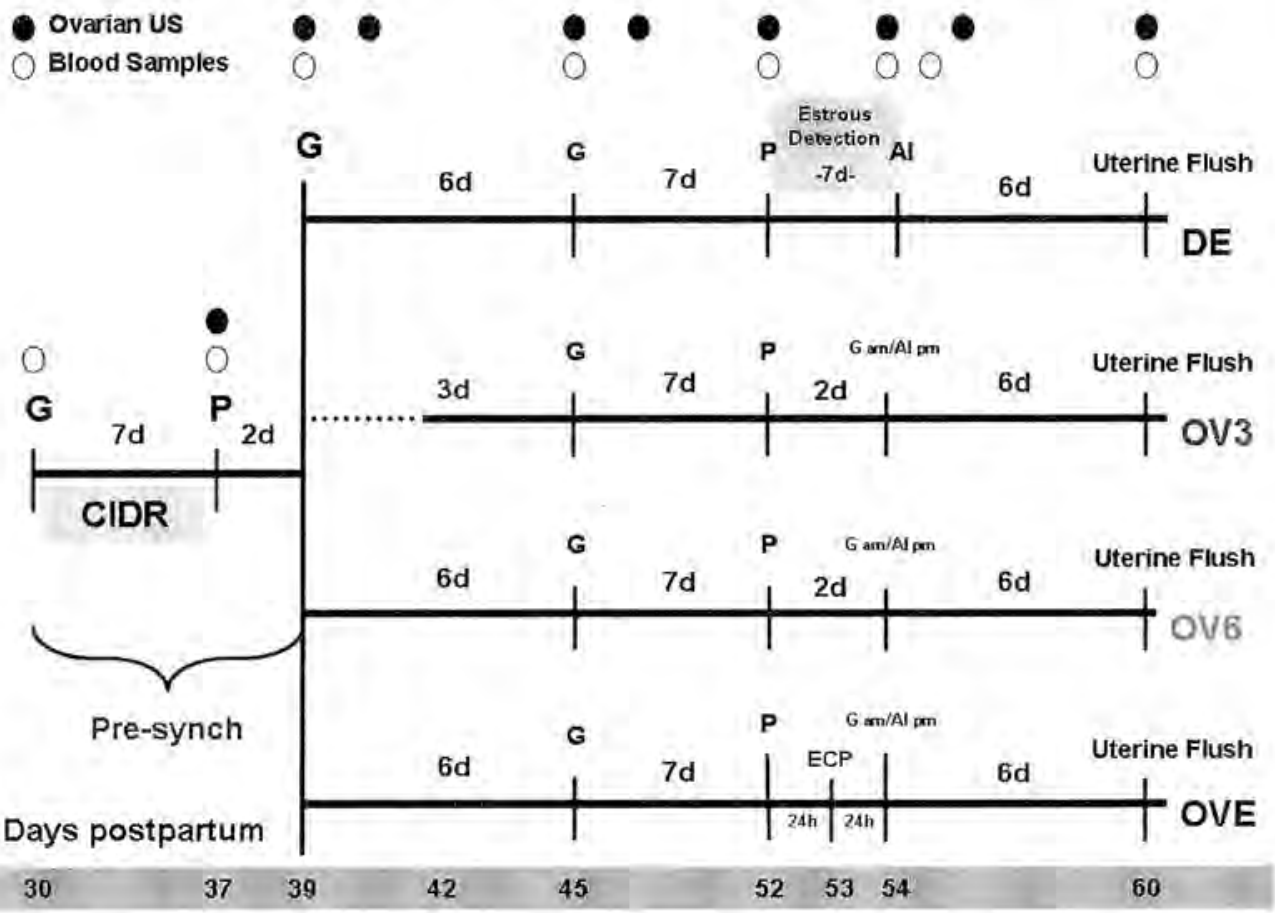

Fig. 1. Protocol to examine the effects of follicle dynamics on fertilization and embryo quality (Cerriet al. 2005a). $\mathrm{Al}=$ artificial insemination; $\mathrm{DE}=$ insemination upon detection of estrus; $\mathrm{G}=$ injection of $\mathrm{GnRH} ; \mathrm{P}=$ injection of $\mathrm{PGF}_{2 \alpha^{\prime}} \mathrm{OV} 3=$ Ovsynch protocol initiated on day 3 of the estrous cycle; OV6 = Ovsynch protocol initiated on day 6 of the estrous cycle; OVE = Ovsynch protocol initiated on day 6 of the estrous cycle and with supplemental estradiol; ECP - supplemental estrogen, estradiol cypionate; Pre-synch = pre-synchronization of the estrous cycle; US = ultrasonography

the total structures recovered, the proportion of embryos graded as excellent and good was reduced in cows that began the Ovsynch protocol on day 3 (OV3) of the cycle (Table 1). Similarly, there was a decrease in the proportion of excellent and good embryos as a proportion of the fertilized ova collected for cows in the OV 3 group. Both the degree of development (the number of blastomeres per embryo) and the viability (proportion of blastomeres that were alive) of the embryos were reduced in the OV3 group (Table 1). Insemination at DE did not improve fertilization rates or embryo quality. The TAl compromised embryo quality when the protocol reduced the number of cows ovulating in response to the first injection of GnRH (OV3). Consequently, the OV3 protocol resulted in prolonged dominance of the ovulatory follicle at Al.

These findings substantiate the importance of regulating follicle dynamics to optimize the period of follicle dominance to obtain high quality embryos. Increasing concentrations of estradiol via an injection of ECP prior to the induction of ovulation with GnRH at $48 \mathrm{~h}$ after the injection of $\mathrm{PGF}_{2 \alpha^{\prime}}$ did not appear to improve fertilization rates or embryo quality. Perhaps supplemental estradiol would be more beneficial if given in the proestrus period when a follicle is allowed to develop to mature ovulatory potential. 
Table 1. Effect of four artificial insemination protocols on embryos recovered from ulerine flushings at day 6 after Al (Cerri et al. 2005a).

\begin{tabular}{lcccc}
\hline & DE & OV3 & Treatment & OVE \\
\hline $\begin{array}{l}\text { Percent grades } 1 \text { and } 2 \text { of } \\
\text { recovered structures }\end{array}$ & 61.0 & 40.0 & 72.0 & 65.9 \\
$\begin{array}{l}\text { Percent grades } 1 \text { and } 2 \text { of } \\
\text { recovered embryos }\end{array}$ & 71.4 & 47.0 & 83.7 & 74.3 \\
$\begin{array}{l}\text { Total number of blastomeres } \\
\text { Proportion of live blastomeres }\end{array}$ & $42.3 \pm 3.39$ & $29.7 \pm 3.44$ & $42.5 \pm 3.29$ & $44.1 \pm 3.16$ \\
\hline
\end{tabular}

${ }^{a}$ Detected estrus $(D E)=G \mathrm{nRH}$ on day 6 of the estrous cycle, followed by $\mathrm{PGF}_{2 \mathrm{a}} 7$ days later and $\mathrm{Al}$ at estrus; Ovsynch (GnRH, followed by $\mathrm{PGF}_{z \alpha} 7$ days later, then 2 days later $\mathrm{GnRH}$ followed by a timed $\mathrm{Al} 12 \mathrm{~h}$ later) as OV3, OV6 and OVE, which correspond to the injection of the first GnRH on day 3, 6 and 6 of the estrous cycle, respectively, but OVE also received an injection of $0.5 \mathrm{mg}$ of estradiol cypionate $36 \mathrm{~h}$ before the timed $\mathrm{Al}$.

$6 \mathrm{P}<0.01,{ }^{2} \mathrm{P}<0.05$

\section{Follicle size and estradiol concentrations during the periovulatory period}

The injection of GnRH at $48 \mathrm{~h}$ after $\mathrm{PGF}_{2 \alpha}$ is at a time that reduces the occurrence of a spontaneous estrus but induces a synchronized ovulation permitting TAI. However, injection of GnRH at $48 \mathrm{~h}$ after $\mathrm{PGF}_{2 \alpha}$ causes a reduction in plasma estradiol concentrations and a slight rise in plasma progesterone concentrations (Thatcher \& Chenault 1976); the increase in plasma progesterone concentrations was not evident when GnRH was injected at $60 \mathrm{~h}$. When groups of lactating dairy cows were synchronized for estrus following injections of GnRH and PGF ${ }_{2 \alpha}$ given 7 days apart, the mean occurrence of estrus was at $72 \mathrm{~h}$ after PGF 2 ; time indicative of a fully functional follicle with a mean diameter of $15.7 \mathrm{~mm}$ (Badinga et al. 1994). Injections of GnRH prior to $72 \mathrm{~h}$ would induce ovulation of a smaller size follicle that might not be fully developed and may have prematurely decreased concentrations of estradiol as a consequence of luteinization of the granulosa cells. It is typical for cows inseminated to an Ovsynch protocol to have reduced estrogenic tone at the time of Al. Injection of $\mathrm{GnRH}$ to induce ovulation initiates a preovulatory $\mathrm{LH}$ surge before some cows appear to have developed dominant follicles that are physiologically mature (Perry et al, 2005). In beef cows, GnRH-induced ovulation of these smaller sized immature follicles caused a decrease in PR because of increased late embryonic/fetal losses (Perry et al. 2005).

An additional means to enhance the programmed proestrus period is to further delay the injection of the second GnRH injection of the Presynch-Ovsynch protocol until $72 \mathrm{~h}$ after the

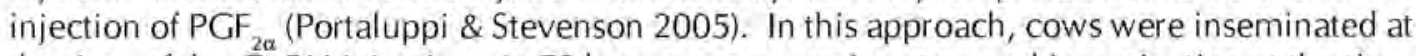
the time of the GnRH injection. At $72 \mathrm{~h}$ many cows are in estrus and inseminating at the time of the GnRH injection is a compromise in that those cows not yet expressing estrus and induced to ovulate will be inseminated early relative to ovulation. However, this strategy allows for an extended proestrus period in lactating dairy cows that results in a more mature functional follicle. Delaying the GnRH injection and $\mathrm{Al}$ until $72 \mathrm{~h}$ after $\mathrm{PGF}_{2 \alpha}$ increased PR compared to the Presynch/Ovsynch protocol with $\mathrm{GnRH}$ injection and $\mathrm{Al}$ at $48 \mathrm{~h}$ after $\mathrm{PGF}_{2 \alpha}(31.4 \%>$ $22.8 \%$ ) or $\mathrm{GnRH}$ injection at $48 \mathrm{~h}$ after $\mathrm{PGF}_{2 \alpha}$ and $\mathrm{Al} 24 \mathrm{~h}$ later $(31.4 \%>23.5 \%$ ). Thus extending the proestrus period improved PR (Portaluppi \& Stevenson 2005). In a recent study, however, when cows were given both $\mathrm{GnRH}$ and TAl at either 48 or $72 \mathrm{~h}$ after a PGF -induced $_{2 \alpha}$ luteolysis, PR did not differ even when $1 \mathrm{mg}$ of ECP was given $24 \mathrm{~h}$ after PGF (Table 2; $_{2 \alpha}$ Hillegass et al. 2006). Brusveen et al. (2006) also failed to detect any difference in PR when 
cows were given both GnRH and TAl at either 48 (G48) or $72 \mathrm{~h}$ (G72) after PGF induced luteolysis as part of a Presynch-Ovsynch program. However, PR was improved when the GnRH injection was delayed to $56 \mathrm{~h}$ (G56) followed by TAl $16 \mathrm{~h}$ later (that is, at $72 \mathrm{~h}$ ). The G56, PR of $36.2 \%$ at day $31-33$ post-Al was greater than $26.7 \%$ and $27.2 \%$ for G48 and $\mathrm{G} 72$, respectively. The beneficial effect of $\mathrm{GnRH}$ at $56 \mathrm{~h}$ prior to TAl at $72 \mathrm{~h}$ is most likely due to a more optimal stage of follicle development at the time of the GnRH injection ( $56 \mathrm{~h}$ compared to 48 h) combined with the proper timing of insemination that allows capacitated sperm to be at the site of fertilization when the cows ovulate.

Table 2. Effect of timed $\mathrm{Al}$ at 48 or $72 \mathrm{~h}_{\text {after }} \mathrm{PGF}_{2 \alpha}$ and treatment with estradiol cypionate (ECP) on reproductive responses of dairy cows (Hillegass et at. 2006).

\begin{tabular}{|c|c|c|c|c|c|c|c|}
\hline & \multicolumn{4}{|c|}{ Treatment ${ }^{3}$} & & & \\
\hline & \multicolumn{2}{|c|}{ CoSynch 48} & \multicolumn{2}{|c|}{ CoSynch 72} & \multicolumn{3}{|c|}{$\mathrm{P}$ value $^{\mathrm{b}}$} \\
\hline & No ECP & $\overline{E C P}$ & No ECP & $\overline{E C P}$ & $\cos$ & ECP & $\operatorname{COS}^{*} E C P$ \\
\hline Cows, n & 240 & 244 & 246 & 240 & & & \\
\hline Estrus at Al, \% & 33.3 & 59.8 & 49.8 & 79.6 & 0.001 & 0.001 & NS \\
\hline Pregnant $38 \mathrm{~d}, \%$ & 42.1 & 46.5 & 46.4 & 43.7 & 0.77 & 0.83 & NS \\
\hline
\end{tabular}

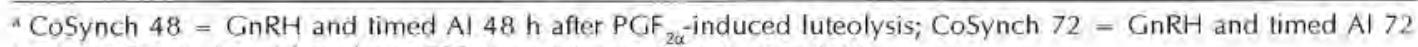
$\mathrm{h}$ after $\mathrm{PGF}_{2 \alpha}$-induced luteolysis; ECP (T mg) injected $24 \mathrm{~h}$ after PGF

${ }^{b} \operatorname{CoS}=$ effect of $\operatorname{CoS} y n c h ; E C P=$ effect of estradiol cypionate; $\operatorname{CoS}^{2} \mathrm{ECP}=$ interaction between $\operatorname{CoS}$ and $\mathrm{ECP}$.

\section{Supplemental estradiol in the periovulatory period}

In a low progesterone environment, during late diestrus and proestrus, exogenous estradiol can stimulate hypothalamic secretion of $\mathrm{GnRH}$ thereby inducing a $\mathrm{LH}$ surge and ovulation. The estradiol-induced LH surge mimics a spontaneous surge in that it lasts for approximately $10 \mathrm{~h}$ : twice the duration of a GnRH-induced surge of LH. Estradiol cypionate (ECP), an esterified form of estradiol-17ß, has been used to induce ovulation as a modification of the PresynchOvsynch program (Pancarci et al. 2002; Cerri et al. 2004). Cows were pre-synchronized with two injections of $\mathrm{PGF}_{2 a}$ given 14 days apart with the TAl program beginning 14 days after the second injection of $\mathrm{PGF}_{20}$ and using ECP to induce ovulation (Pancarci et al. 2002). Cows were injected with GnRH followed by $\mathrm{PGF}_{2 \alpha} 7$ days later. The ECP ( $1 \mathrm{mg}, \mathrm{i} . \mathrm{m}$.) was injected $24 \mathrm{~h}$ after PGF $_{2 \alpha}$ and cows received TAI 48 h later or at detected estrus if it occurred prior to $48 \mathrm{~h}$. In lactating dairy cows, the frequencies of detected estrus and ovulation after ECP were $75.7 \%$ and $86.5 \%$, respectively (Pancarci et al. 2002). Estrus occurred at $29.0 \pm 1.8 \mathrm{~h}(\mathrm{n}=28)$ after ECP. Mean intervals to ovulation were $55.4 \pm 2.7 \mathrm{~h}$ after ECP and $27.5 \pm 1.1 \mathrm{~h}$ after onset of estrus. The interval from ECP injection to ovulation had a rather large coefficient of variation of $27.4 \%$. This lead to the recommendation to inseminate cows at all detected estruses occurring prior to $48 \mathrm{~h}$ and TAI the remaining cows at $48 \mathrm{~h}$ after the ECP injection.

Lactating dairy cows have reduced concentrations of plasma estradiol in the preovulatory period and a reduced intensity of estrus (De la Sota et al. 1993; Sartori et al. 2002a) therefore the elevation of plasma estradiol concentrations following ECP injection will supplement for a lactational induced deficiency in estradiol. If cows are anovulatory (for example, anestrus or have not developed positive estradiol feedback) then the ECP modified Ovsynch program may not be as effective as the GnRH based Ovsynch program in which GnRH causes the direct secretion of $\mathrm{LH}$. The greater occurrence of estrus, enhanced uterine tone and ease of insemination are practical advantages with the use of the Presynch/ECP modified Ovsynch program. 
Cerri et al. (2004) clearly demonstrated that lactating dairy cows subjected to a presynchronized/ECP modified Ovsynch with a TAI had increased proportions of cows in estrus, as well as greater conception and pregnancy rates compared with cows inseminated following detected estrus induced by a presynchronized/Gn RH-PGF ${ }_{2 \alpha}$ (that is, 7 day interval) protocol. Fertility responses to the presynchronized/ECP modified Ovsynch protocol were improved when lactating cows were observed in estrus after ECP treatment. Occurrence of estrus in both groups was associated with cyclic status and the size of the preovulatory follicle determined at $48 \mathrm{~h}$ after ECP. As cows inseminated following the presynchronized/ECP modified Ovsynch protocol had greater conception rates, it is possible that supplemental estradiol given during proestrus in the form of ECP enhanced the fertility of these high-producing dairy cows.

The dynamics of estradiol exposure during the proestrus period prior to either spontaneous or induced preovulatory surges of LH need to be evaluated precisely to determine whether estradiol supplementation enhances conception and pregnancy rates. The variables to be examined in the proestrus period following an injection of $\mathrm{PGF}_{2 a}$ include the timing of the estradiol treatment relative to both follicle maturity (size, estrogenic status et cetera) and the preovulatory surge of $\mathrm{LH}$. The surge of LH initiates oocyte maturation and luteinization of the follicular cellular components leading to a decrease in estradiol secretion and ovulation. Clearly the findings of Cerri et al. (2004) of enhanced conception and pregnancy rates with the use of ECP was in association with enhanced plasma estradiol concentrations during a programmed proestrus period of $53 \mathrm{~h}$ (that is, mean interval from the injection of $\mathrm{PGF}_{2 \alpha}$ to the onset of estrus or the $\mathrm{LH}$ surge). The mean diameter of preovulatory follicles at $48 \mathrm{~h}$ after ECP was $18 \mathrm{~mm}$ in diameter. Proestrus follicles that matured earlier, based on detected estruses prior to $48 \mathrm{~h}$, were accommodated by prompt Al.

In subsequent studies, ECP was used in conjunction with a GnRH injection to control more precisely the timing of estradiol injections relative to the $\mathrm{LH}$ surge; however, reproductive responses were not improved (Cerri et al. 2005a; Sellars et al. 2006; Hillegass et al. 2006). An injection of $0.5 \mathrm{mg}$ ECP $24 \mathrm{~h}$ after $\mathrm{PGF}_{2 \alpha}$ injection, which was $24 \mathrm{~h}$ prior to an injection of $\mathrm{GnRH}$, failed to increase either fertilization rates or embryo quality at day 6 after TAI (Table 1; Cerri et al. 2005a). Pregnancy rates were not increased when $0.5 \mathrm{mg}$ ECP were injected concurrently with $\mathrm{GnRH}$ at $48 \mathrm{~h}$ after $\mathrm{PGF}_{2 \alpha}$ injection when compared to a standard Ovsynch protocol (Sellars et al, 2006). In contrast to the experiment of Cerri et al. (2004), the dose of ECP was less $(0.5 \mathrm{mg}$ versus $1.0 \mathrm{mg})$ and plasma estradiol concetrations were elevated at the time the follicle was induced to undergo luteinization in response to the LH surge induced by the concurrent injection of $\mathrm{GnRH}$. Although sizes of the preovulatory follicles at $48 \mathrm{~h}$ were the same among the experiments (Cerri et al. 2004; 2005a; Sellars et al. 2006), the approximate proestrus periods before the induced surge-like release of $\mathrm{LH}$ differed (that is, 53, 48 and $48 \mathrm{~h}$, respectively) as did the period of elevated plasma estradiol concentrations prior to the LH surge $(\sim 29,24$ and 0 h, respectively). When Souza etal. (2005) supplemented lactating dairy cows with $1 \mathrm{mg}$ of estradiol-17ß at $8 \mathrm{~h}$ prior to the induction of ovulation in the Ovsynch program, treatment with estradiol $-17 B$ increased circulating estradiol concentrations ( $18.4 \pm 4.6$ units, $\mathrm{n}=8$ vs. $2.94 \pm 0.6$ units, $\mathrm{n}=8 ; \mathrm{P}<0.01)$ and expression of estrus $(78.5 \%, \mathrm{n}=302$ vs. $42.4 \%$, $n=290 ; P<0.01$ ). Thus induction of a sharp rise and decline in plasma estradiol concentrations improved PR to TAI in cows during the cool season $\left(<21^{\circ} \mathrm{C}\right)(50.9 \%, n=116 \mathrm{vs} .34 .6 \%$, $n=108 ; P<0.02$ ). Cows classified as anovular had greater $P R$ when treated with estradiol $17 \AA$ In addition, cows with intermediate-sized ovulatory follicles (15-20 $\mathrm{mm}$ in diameter with single ovulation, $n=416)$ tended $(P=0.06)$ to have greater $P R$ when supplemented with estradiol-17ß prior to GnRH-induced ovulation. These data support the findings of Cerri et al. (2004) and suggest that the response to supplemental estradiol depends upon cyclic status, season and size of the ovulatory follicle. 


\section{Use of ovulatory control programs as a platform to improve pregnancy rates}

Ovulatory control systems have provided a platform for investigators to quantitatively elucidate the factors that are limiting herd fertility, and such a platform provides a reference base to test strategies that may improve PR. The ability to synchronize follicle development and CL regression coupled with the precise timing of ovulation allows for synchronous inseminations or transfer of embryos. Consequently, the management and biological factors regulating reproductive performance can be examined and systems developed to improve PR in what is currently considered a sub-fertile population of lactating dairy cows.

The impact of anovulatory cows and body condition scores on pregnancy rates and embryo losses

The interrelationships among parity, body condition score (BCS; 1 to 5 scale), milk yield, $\mathrm{Al}$ protocol (inseminated at estrus or TAI) and cyclicity (cyclic or anovular) were evaluated with respect to their impacts on PR and embryonic survival following the first postpartum $\mathrm{Al}(\mathrm{n}=5,767)$ in nine studies on five dairy farms (Rutigliano \& Santos 2005). All farms and cows had records on $\mathrm{BCS}$ at calving and at AI. For all farms, cows were inseminated at first service either upon detection of a synchronized estrus or at TAI in association with a Presynch-Selectsynch or Presynch-Ovsynch or Presynch-Heatsynch program (Thatcher et al. 2004). Pre-synchronization entailed two PGF injections given 14 days apart with the TAI or estrous synchronization protocol initiated 12 to 14 days after the pre-synchronization. Effects of parity (that is, primiparous and multiparous) were evaluated in all of the studies and farms. Milk yield was determined once (eight studies) or twice monthly (one study). On two of the five farms used in the nine studies, cows were milked either twice or thrice daily (that is, on one farm, cows were milked thrice daily in three of the five studies whilst on another farm they were milked thrice daily in two of four studies).

Occurrence of cyclicity was greater for multiparous than primiparous cows at 65 days postpartum $(81.8 \%$ vs, $69.5 \% ; \mathrm{P}<0.001)$. In addition to parity, cyclicity was also influenced by milking frequency (twice $=82.7 \%$ vs. thrice $=68.7 \% ; \mathrm{P}<0.01$ ), BCS at calving and at $\mathrm{AI}, \mathrm{BCS}$ change and milk yield. However, milk yield, BCS at calving and the Al protocol had no effect $(P>0.10)$ on PR at 30 and 58 days after $\mathrm{Al}$ or pregnancy loss. More $(\mathrm{P}<0.001)$ cyclic than anovular cows were pregnant at $30(40.0 \%$ v $5.28 .3 \%)$ and $58(34.2 \%$ vs. $23.0 \%)$ days after $\mathrm{Al}$ and anovulation tended $(\mathrm{P}=0.09)$ to increase pregnancy loss $(14.5 \% \mathrm{vs}, 18.6 \%)$ between 30 and 58 days of gestation. Pregnancy loss was highest $(22.5 \%$ vs. $16.8 \%$ vs. $12.2 \% ; \mathrm{P}<0.01)$ and conception rates at day 58 lowest $(21.7 \%$ vs. $30.4 \%$ vs. $35.6 \%$; $P<0.01)$ in cows that lost $\geq 1$ unit of $B C S$ than those that lost $<1$ or experienced no change in BCS from calving to Al. Likewise, a greater BCS at $\mathrm{Al}(\geq 3.75 \mathrm{vs}$. 3.0 to 3.5 vs. $\leq 2.75)$ increased conception rates at $30(46.4 \%$ vs, $40.1 \%$ vs. $33.9 \%$, respectively; $\mathrm{P}<0.01)$ and $58(41.8 \%$ vs. $34.6 \%$ vs. $27.9 \% ; \mathrm{P}<0.01)$ days after AI. Consequently, minimizing loss of BCS after calving and improving cyclicity early postpartum are expected to increase PR and enhance embryonic survival. The AI protocol and milk yield did not affect pregnancy and embryonic survival after the first postpartum AI. This summary of studies with repeated measurements of BCS dynamics and anovulatory status in association with PR is in agreement with other studies indicating that pregnancy rates to first timed insemination are less for anovulatory cows (Moreira et al. 2001; Cordoba \& Fricke 2001; Gumen et al. 2003).

\section{Supplemental progesterone for anovular cows}

Methods to improve fertility of anovular cows, such as the use of supplemental progesterone, have proven inconsistent in high-producing dairy cows. Use of an intravaginal progesterone 
insert increased the induction of cyclicity in anovular cows between 49 and 62 days postpartum (30.8 vs 46.2\%; P<0.01: Chebel et al. 2006) but failed to improve PR in cyclic and anovular cows. Galvao et al. (2004) incorporated an intravaginal progesterone insert, containing $1.38 \mathrm{~g}$ of progesterone, in a TAI protocol but the progesterone insert did not improve PR or embryo survival in anovular cows. Previously, incorporation of an intravaginal progesterone insert into a TAI protocol improved PR in one of two experiments (El-Zarkouny et al. 2004) but in none of the experiments did the progesterone insert improve PR of anovular cows. The inconsistency in reproductive performance after progesterone supplementation is quite intriguing and possibly related to the low concentrations of progesterone induced by the CIDR in high-producing lactating cows (Cerri et al. 2005b).

\section{Embryotrophic actions of bovine somatotropin at first Al}

Exogenous bovine somatotropin (bST) increased PR (for example, 57.0\% > 42.6\%: Moreira et al. 2001) when administered as part of a Presynch-Ovsynch TAI protocol (that is, bST was given either at the first injection of $\mathrm{GnRH}$ or at TAl) in cyclic lactating dairy cows for the first Al postpartum or in protocols involving cows being inseminated at detected estrus (Moral es-Roura et al. 2001; Santos et al. 2004; Starbuck et al. 2006). Furthermore, pregnancy losses were reduced in cows that received bST at the time of the first GnRH injection of either a PresynchOvsynch TAl protocol or synchronization using GnRH followed 7 days later by PGF $_{2 \alpha}$ with cows inseminated at detected estrus (Santos et al. 2004). The study of Morales-Roura et al. (2001) involved cows identified as having three or more prior inseminations. Pregnancy rates were stimulated when bST was given at estrus and again 10 days later. As bST was effective at AI, it is likely that bST stimulated fertilization, embryonic development and survival following $\mathrm{Al}$ in lactating dairy cows. Subsequent in vitro and in vivo studies indicated that both $\mathrm{GH}$ and IGF-I stimulated fertilization and blastocyst development (Moreira et al. 2002a;b) as well as embryo cell number (Moreira et al. 2002a).

An additional study utilized a pre-synchronization protocol followed by Ovsynch and TAI as a platform to examine the effect of bST (injected at TAI and 11 days later) on conceptus development and endometrial gene expression at day 17 after TAI, as well as daily hormonal responses between TAI (=day 0) and day 17 (Bilby et al. 2006a; b; Thatcher et al. 2006). There were increases in conceptus length $(45>34 \mathrm{~cm}$ ), interferon- $\tau$ concentrations in uterine luminal flushings $(9.4>5.3 \mu \mathrm{g})$ and enhanced embryo survival based on a greater PR at day 17 $(83 \%>40 \%)$ in animals treated with bST. When the contents of interferon- $\tau$ in the uterine flushings were adjusted for the length of the extra-embryonic membranes as a covariate, the difference due to bST was no longer significant. Thus a greater uterine pool size of interferon$\tau$ in bST-treated cows appears to be due to a greater size of the conceptuses at day 17 . Treatment with bST enhanced the abundancies of both IGF-II and PGES mRNAs whilst it decreased PGFS mRNA in the endometrial tissue of day 17 pregnant cows compared to pregnant cows not treated with bST. Collectively, these uterine and conceptus responses likely contribute to enhancing embryo survival in lactating cows at first Al when administered at the proper time in a programmed and synchronous ovulation with insemination.

\section{Timed embryo transfer}

An additional use of the Ovsynch protocol is to control the time of ovulation as a platform to carry out a timed embryo transfer in recipient lactating dairy cows. Since the Ovsynch program can be used successfully to synchronize ovulation rate in a significant number of cows (that is, 
$\sim 85 \%$ ), it can be used for a synchronized transfer of either fresh or frozen embryos produced from superovulated donors or by in vitro production (IVP). The practicality and efficiency of recipient management is further improved by identifying, at the time of embryo transfer, whether the synchronized recipient has a $\mathrm{CL}$ and a dominant follicle confirmatory of a synchronized ovulation to the second injection of $\mathrm{GnRH}$ of the Ovsynch protocol. Use of a Presynch-Ovsynch protocol or some appropriate modification for pre-synchronization would further improve the percentage of recipients with a synchronized ovulation.

The percentage of viable embryos (that is, excellent and good quality) recovered at day 6 after Al, following a pre-synchronization program that preceded an Ovsynch protocol implemented at day 6 of the estrous cycle, was $66.5 \%$ (Table 1, DE $=61 \%$ and OV $6=72 \%$; Cerri et al. 2005a). Hence there is a considerable number of potential pregnancy losses by day 6 and this is even greater in lactating dairy cows exposed to heat stress (22\% with grades 1,2 and 3 embryos; Sartori et al. 2002b). Thus timed embryo transfer of excellent to good grade embryos would be a logical means to by-pass these early embryo losses prior to day 6 or 7 in lactating dairy cows.

Two studies completed in Florida during the summer heat stress season evaluated timed embryo transfer following the second injection of GnRH in the Ovsynch protocol; embryos were transferred to recipients either at day 7.5 (Ambrose et al. 1999) or day 8 (Al-Katanani et al. 2002). Fresh IVP embryos increased PR compared to TAI $(16.6 \%>5.6 \%)$. Frozen-thawed IVP embryos resulted in PR comparable to the TAI control groups (that is, $5.6 \%$ ). Consequently, processes associated with the freezing and thawing of IVP embryos are not optimal for transfer of embryos during conditions of heat stress in lactating dairy cows. However, it is clear that under heat stress conditions in Florida, the well characterized detrimental effects of high temperature on early embryo development can be by-passed partially with the use of timed embryotransfer.

Based on the observations that IGF-I stimulates blastocyst development during in vitro culture (Moreira et al. 2002a), Block et al. (2003) documented clearly that embryos cultured with IGF-I subsequently transferred fresh into recipients (timed embryo transfer on day 8 after the second GnRH of an Presynch-Ovsynch protocol) resulted in greater PR during summer heat stress. This beneficial effect of IGF-I exposure in culture, that results in increased PR following embryo transfer of fresh embryos, occurred in the summer heat stress season (day 41-49 PR: + IGF-I, $28 / 67=41.8 \%$ vs. - IGF-I, $13 / 71=18.3 \%$ ) but not during the cooler season (day $41-49$ PR: + IGF-1, $16 / 73=21.9 \%$ v5. - IGF-I, 21/74 $=28.4 \%$ ) of the year (Block \& Hansen 2006).

Since early embryonic viability is reduced in lactating dairy cows (Sartori et al. 2002b), Sartori and coworkers (2006) hypothesized that embryo transfer would improve PR in lactating dairy cows. Ovulation was synchronized with a modified Ovsynch program (GnRH followed at 7 days with $\mathrm{PGF}_{2 \alpha}$ and then 3 days later with $\mathrm{GnRH}$ ) and then the cows were either inseminated at the time of the second $\mathrm{GnRH}$ injection or they received fresh or frozen embryos (classified as excellent or good quality from superovulated cows or heifers) at day 7 after the second GnRH injection. Pregnancy rates at days 60-66 for cows that had a synchronized ovulation did not differ between $\mathrm{Al}(31.2 \%)$ and embryo transfer $(30.7 \%)$. The authors suggested that lactating dairy cows might have other reproductive problems that may not be solved by embryo transfer. These could include subclinical endometritis, carry over effects of negative energy balance or hormonal imbalances that collectively may compromise the uterine environment for optimal embryo development after embryo transfer. In fact, 30 to $50 \%$ of lactating dairy cows have subclinical endometritis, characterized by increased presence of polymorphonuclear neutrophils in the uterine lumen after 40 days postpartum, which are associated with reduced PR (Sheldon et al. 2006). 
The comparison between animals that were inseminated versus a transferred embryo is insightful. For all cows that had a synchronized ovulation of a single ovulatory follicle, those with a smaller size ovulatory follicle $(10-15 \mathrm{~mm}$ in diameter) had lower PR at days 25-32 when inseminated compared to those receiving embryo transfer $(23.7 \%<42.3 \%$; $P<0.05)$. Similar results were observed when pregnancy was diagnosed on days $60-66(18.4 \%<38.5 \%$; $P<0.05)$. In contrast, no differences between groups were detected for medium- and large-size ovulatory follicles (Sartori et al. 2006). For all single-ovulatory cows, those classified as having smaller size ovulatory follicles had lower concentrations of progesterone at day 7 than those cows ovulating medium - or larger-size ovulatory follicles $(1.59 \mathrm{ng} / \mathrm{ml}<2.00 \mathrm{ng} / \mathrm{ml}$ and $2.13 \mathrm{ng} / \mathrm{ml}$, respectively). It is plausible to suggest that the lower concentrations of progesterone associated with the synchronized ovulation of a small size ovulatory follicle results in a sub-optimal rise in progesterone that alters early embryo development resulting in a reduced PR. This early period of developmental sensitivity appears to be by-passed with the transfer of excellent or good grade embryos to single ovulation recipient cows that are lactating.

A possible method to overcome the formation of sub-functional luteal tissue is the induction of accessory CL early in diestrus. Santos et al. (2001) injected 3,300 IU of hCG in lactating cows 5 days after $\mathrm{Al}$ following detection of a synchronized estrus and cows receiving hCG had an increased number of $\mathrm{Cl}$ and increased plasma progesterone concentrations. Pregnancy rates on days 28,42 , and 90 were improved by hCG treatment but late embryonic and fetal losses remained unaltered. Benefits of hCG treatment were clearly demonstrated in cows that were losing BCS between Al and pregnancy diagnosis. Nishigai et al. (2002), utilizing embryo recipient cows, demonstrated that hCG induction of an accessory $C L$ and a subsequent increase in plasma progesterone concentration increased PR. Pregnancy rate in cows receiving hCG on day 6 was higher $(67.5 \%)$ than in control cows $(45.0 \%)$ or cows receiving hCG on day 1 $(42.5 \%)$ after $\mathrm{Al}$.

\section{Conclusions}

The management of reproductive processes in the high producing dairy cow to optimize PR can be achieved partially through implementation of a timed Al program characterized by sequentially controlling follicle turnover in concert with induced regression of the corpus luteum and timely induction of ovulation. Such systems partially optimize the proestrous period and supplemental estradiol further increases PR. Components of the postpartum period, such as parity, dynamic changes in body condition score, anovulation and uterine health, influence PR and embryo losses. Management of the post-ovulatory dialogue between embryonic and uterine tissues should enhance embryo development in lactating dairy cows, as demonstrated by the timely injection of hCG to increase circulating progesterone concentrations and the enhancement of conceptus development and PR in response to bST. Timed embryo transfer is a means to by-pass inefficiencies in fertilization and early embryo development associated with heat stress and has provided a platform to demonstrate the in vivo beneficial effects of culturing in vitro produced embryos with IGF-I. Embryos produced in vitro that are cultured in the presence of IGF-I result in greater PR post-transfer during seasonal periods of heat stress. Conversely, the lack of an improvement in PR of timed embryo transfers in the cool season compared to timed insemination indicates that there may be potential arrays of factors compromising fertility in lactating dairy cows beyond the optimization of the periovulatory period. 


\section{Acknowledgements}

Research conducted by the authors was supported by grants from the National Research Initiative of the USDA Cooperative State Research, Education, and Extension Service (Competitive Grant no. 2004-35203-14137; Grant no. 98-35203-6367); Florida-Georgia Milk Checkoff Program; Center for Food Animal Health of the University of California Davis, USDA Formula Funds (Project no. CALV-AH-214); National Association of Animal Breeders; Pfizer Animal Health; and Select Sires.

\section{References}

Al-Katanani YM, Drost M, Monson RL, Rutledge II, Krininger CE III, Block J, Thatcher WW \& Hansen PJ 2002 Pregnancy rates following timed embryo transfer with fresh or vitrified in vitro produced embryos in laclating dairy cows under heal stress conditions. Theriogenology 58 171-182.

Ambrose JD, Drost M, Monson RL, Rutledge IJ, Leibfried-Rutledge ML, Thatcher MJ, Kassa T, Binelli M, Hansen PJ, Chenoweth PJ \& Thatcher WW 1999 Efficacy of timed embryo transfer with fresh and frozen in vitro produced embryos to increase pregnancy rates in heat stressed dairy cattle. lournal of Dairy Science $\mathbf{8 2}$ 2369-2376.

Austin EJ, Mihm M, Ryan MP, Williams DH, Roche JF 1999 Effect of duration of dominance of the ovulatory follicle on onset of estrus and fertility in heifers. Journal Animal Science $772219-2226$.

Badinga L, Thatcher WW, Wilcox CI, Morris G, Entwistle K \& Wolfenson D 1994 Effecl of season on follicular dynamics and plasma concentrations of estradiol-1 $7 ß$, progesterone and luteinizing hormone in lactating Holstein cows. Theriogenology $421263-$ 1274 .

Bilby TR, Sozzi A, Lopez MM, Silvestre F, Ealy AD, Staples CR \& Thatcher WW 2006a Pregnancy, bST and omega-3 fally acids in lactating dairy cows: I. ovarian, conceptus and growth hormone - ICF system response. Journal of Dairy Science $\mathbf{8 9} 3360-$ 3374.

Bilby TR, Guzeloglu A, MacLaren LA, Staples CR \& Thatcher WW 2006b Pregnancy, bST and omega-3 fatty acids in lactating dairy cows: II. Endomelrial gene expression related to mainlenance of pregnancy. Journal of Dairy Science 89 3375-3385.

Block J \& Hansen PJ 2006 Effecl of the addition of insulin-like growth factor-1 to embryo culture medium on pregnancy rates following limed embryo Iransfer in lactating dairy cows. Journal of Dairy Science 89 (Suppl. 1) 287.

Block J, Drost M, Monson RL, Rutledge IJ, Rivera RM, Paula-Lopes FF, Ocon OM, Krininger CE III, Liu J \& Hansen PJ 2003 Use of insulin-like growth factor-1 during embryo culture and treatment of recipients with $\mathrm{GnRH}$ to increase pregnancy rates following the transfer of in vitro produced embryos to heatstressed, lactaling cows. Journal Animal Science $\mathbf{8 1}$ 1590-1602.
Brusveen DJ, Cunha AP, Silva CD, Cunha PM, Sterry RA, Silva EPB, Guenther IN \& Wiltbank MC 2006 Effects on conception rates of lactating dairy cows by altering the time of the second $\mathrm{GnRH}$ and $\mathrm{Al}$ during Ovsynch. Journal Dairy Science 89 (Suppl. 1) 150.

Cerri RLA, Santos JEP, Juchem SO, Galvâo KN \& Chebel RC 2004 Timed artificial insemination with estradiol cypionate or insemination at estrus in highproducing dairy cows. Journal of Dairy Science $\mathbf{8 7}$ 3704-3715.

Cerri RLA, Rutigliano HM, Bruno RGS, Chebel RC \& Santos JEP 2005a Effect of artificial insemination (Al) protocol on fertilization and embryo quality in highproducing dairy cows. Journal of Dairy Science $\mathbf{8 8}$ (Suppl. 1) 86.

Cerri RLA, Rutigliano HM, Bruno RGS \& Santos JEP 2005 b Progesterone (P4) concentrations and ovarian response after insertion of a new or a $7 \mathrm{~d}$ used intravaginal P4 inserl (IPI) in proestrus lactating cows. lournal of Dairy Science $\mathbf{8 8}$ (Suppl. 1) 37.

Chebel RC, Santos JEP, Cerri RLA, Rutigliano HM \& Bruno RGS 2006 Reproduction in dairy cows following progesterone insert presynchronization and resynchronization protocols. Journal of Dairy Science 89 4205-4219.

Cordoba MC \& Fricke PM 2001 Evaluation of two hormonal prolocols for synchronization of ovulation and timed artificial insemination in dairy cows managed in grazing-based dairies. Journal Dairy Science $\mathbf{8 4}$ 2700-2708.

De La Sota RL, Lucy MC, Staples CR \& Thatcher WW 1993 Effects of recombinant bovine somatotrophin (Sometribove) on ovarian function in lactating and nonlaclating dairy cows. Journal of Dairy Science 76 1002-1013.

El-Zarkouny SZ, Cartmill JA, Hensley BA \& Stevenson IS 2004 Pregnancy in dairy cows after synchronized ovulation regimens with or without presynchronization and progesterone. Journal of Dairy Science 87 1024-1037.

Galvao KN, Santos JE, Juchem SO, Cerri RL, Coscioni AC \& Villasenor M 2004 Effect of addition of a progesterone intravaginal insert to a timed insemination protocol using estradiol cypionate on ovulation rate, pregnancy rate, and late embryonic loss in lactating dairy cows. lournal Animal Science 82 3508-3517. 
Gumen A, Guenther IN \& Wiltbank MC 2003 Follicular size and response to Ovsynch versus detection of estrus in anovular and ovular lactating dairy cows. Journal Dairy Science 86 3184-3194.

Hillegass J, Santos JEP, Lima FS \& Sa Filho M 2006 Effect of interval from luteolysis to timed $\mathrm{Al}$ and supplemental estradiol on reproductive performance of dairy cows. In preparation

Morales-Roura IS, Zarco L, Hernandez-Ceron J \& Rodriguez G 2001 Effeccl of short-term trealment with bovine Somatotropin at estrus on conception rate and luteal function of repeat-breeding dairy cows. Theriogenology 55 1831-1841.

Moreira FCO, Risco CA, Mattos R, Lopes F \& Thatcher WW 2001 Effects of presynchronization and bovine somatotropin on pregnancy rates to a timed artificial insemination protocol in lactating dairy cows. Journal of Dairy Science 84 1646-1659.

Moreira F, Paula-Lopes F, Hansen PJ, Badinga L \& Thatcher WW 2002a Effects of growth hormone and insulin-like growth factor-1 on development of in vitro derived bovine embryos. Theriogenology 57 895-907.

Moreira F, Badinga L, Burnley C \& Thatcher WW $2002 \mathrm{~b}$ Bovine somatotropin increases embryonic development in superovulated cows and improves post-transfer pregnancy rates when given to lactating recipient cows. Theriogenology 57 1371-1387.

Navanukraw C, Redmer DA, Reynolds LP, Kirsch JD, Grazul-Bilska AT \& Fricke PM 2004 A modified presynchronization protocol improves fertility to timed artificial insemination in lactating dairy cows. lournal of Dairy Science 87 1551-1557.

Nishigai M, Kamomae H, Tanaka T \& Kaneda Y 2002 Improvement of pregnancy rate in Japanese Black cows by administration of hCG to recipients of transferred frozenthawed embryos. Theriogenology $\mathbf{5 8}$ 1597-1606.

Pancarci SM, Jordan ER, Risco CA, Schouten MJ, Lopes FL, Moreira F \& Thatcher WW 2002 Use of estradiol cypionate in a pre-synchronized timed arlificial insemination program for lactating dairy cattle. Journal of Dairy Science 85 122-131.

Perry GA, Smith MF, Lucy MC, Green IA, Parks TE, MacNeil MD, Roberts AJ \& Geary TW 2005 Relationship befween follicle size at insemination and pregnancy success. PNAS 102 5268-5273.

Portaluppi MA \& Stevenson JS 2005 Pregnancy rates in lactating dairy cows after presynchronization of estrous cycles and variations of the ovsynch protocol. Journal of Dairy Science 88 914-921.

Pursley IR, Kosorok MR \& Wiltbank MC 1997 Reproductive management of laclating dairy cows using synchronization of ovulation. Journal of Dairy Science $80301-306$.

Rutigliano HM \& Santos JEP 2005 Interrelationships among parity, body condition score (BCS), milk yield, Al protocol, and cyclicity with embryonic survival in lactating dairy cows. Journal of Dairy Science $\mathbf{8 8}$ (Suppl 1)178.
Sartori R, Rosa GJM \& Wiltbank MC 2002a Ovarian structures and circulating steroids in heifers and lactating cows in summer and lactating and dry cows in winter. Journal of Dairy 5cience 85 2813-2822.

Sartori R, Sartor-Bergfelt R, Mertens SA, Guenther JN, Parrish IJ \& Wiltbank MC 2002b Fertilization and early embryonic development in heifers and lactating cows in summer and lactating and dry cows in winter. Journal of Dairy Science $\mathbf{8 5}$ 2803-2812.

Sartori R, Gumen A, Guenther IN, Souza AH, Caraviello DZ \& Wiltbank MC 2006 Comparison of artificial insemination versus embryo transfer in lactating dairy cows. Theriogenology 65 1311-1321.

Santos JEP, Thatcher WW, Pool L \& Overton MW 2001 Effect of human chorionic gonadotropin on luteal function and reproductive performance of highproducing lactating Holstein dairy cows. lournal Animal Science 79 2881-2894.

Santos JEP, Juchem SO, Cerri RLA, Galvăo KN, Chebel RC, Thatcher WW, Dei CS \& Bilby CR 2004 Effect of BST and reproductive management on reproductive performance of Holstein dairy cows. Journal of Dairy Science 87 868-881.

Sellars CB, Dalton JC, Manzo R, Day I \& Ahmadzadeh A 2006 Time and incidence of ovulation and conception rates after incorporating estradiol cypionate into a timed artificial insemination protocol. Journal of Dairy Science 89 620-626.

Sheldon MI, Lewis GS, LeBlanc S \& Gilbert RO 2006 Defining postpartum uterine disease in cattle. Theriogenology 65 1516-1530.

Souza AH, Gümen A, Silva EPB, Cunha AP, Guenther JN, Peto CM, Caraviello DZ \& Wiltbank MC 2005 Effect of estradiol-17B supplementation before the last GnRH of the Ovsynch protocol in high producing dairy cows. Journal of Dairy Science $\mathbf{8 8}$ (Suppl. 1) 170 .

Starbuck MI, Inskeep EK \& Dailey RA 2006 Effect of a single growth hormone (rbST) treatment at breed ing on conception rates and pregnancy retention in dairy and beef cattle. Animal Reproduction Science $93349-359$.

Thatcher WW \& Chenault JR 1976 Reproductive physiological responses of cattle to exogenous prostag-

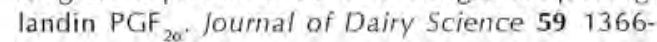
1375.

Thatcher WW, Bartolome JA, Sozzi A, Silvestre F \& Santos JEP 2004 Manipulation of ovarian function for the reproductive management of dairy cows. Veterinary Research Communications 28 111-119.

Thatcher WW, Bilby TR, Bartolome JA, Silvestre F, Staples CR \& Santos JEP 2006 Strategies for improving fertility in the modern dairy cow. Theriogenology 65 30-44.

Vasconcelos JLM, Silcox RW, Pursley JR \& Wiltbank MC 1999 Synchronization rate, size of the ovulatory follicle, and pregnancy rate after synchronization of ovulation beginning on different days of the estrous cycle in lactating dairy cows. Theriogenology $521067-1078$. 